\title{
DEVELOPMENT OF AN ELECTRONIC SENSOR FOR DATE SORTING BASED ON MOISTURE CONTENT
}

\author{
K.M. Ismail ${ }^{1}$. \\ K.A. Al-Gaadi ${ }^{2}$
}

\begin{abstract}
An electronic date moisture sensor utilizing a Wheatstone bridge circuit and an operational amplifier as a signal conditioner was developed. The sensor was designed to produce a voltage output that was proportional to date moisture content. The voltage output was amplified to activate a DC motor, which in turn could be used to operate a date separating device. Samples of dates of four different local types (Sokari, Rawthana, Om Al-Khashab and Nabtit-Aly) were used at different moisture contents to establish a correlation between the sensor voltage output and date moisture contents. The voltage output was found to be proportional to date moisture content. An output of less than $5.5 \mathrm{v}$ was associated with date moisture contents ranging between $2.5 \%$ and $26 \%$. However, the voltage output was higher than $6 \mathrm{v}$ was associated with date moisture contents of $38 \%$ and above.
\end{abstract}

\section{INTRODUCTION}

ates are fruits that are considered to be a traditional agricultural product in the Arab World. They are thought to be very nutritious and very popular fruits in the Kingdom of Saudi Arabia, where individual Saudi consumes, on the average, an annual amount of $35.8 \mathrm{~kg}$ (Saudi Ministry of Agriculture, 2007). The Kingdom of Saudi Arabia is one of the most important countries for date production, where its production in year 2007 was estimated at 982,546 tons (Saudi Ministry of Agriculture, 2008), making it the largest date producer in the world. The high production of dates and the growing demand for good quality dates and date pastries give a huge potential and importance to the date industry in Saudi Arabia. Currently, there are sixty one large date processing plants operating in the country for date grading and packaging, however, the capacities of these

1- Professor at the Univ. of Alex., Dept. of Agric. Eng., Alex., Egypt.

2-Associate Professor at King Saud Univ., Dept. of Agric. Eng., Precision Agriculture Research Chair (PARC), Riyadh, Saudi Arabia. 
plants are limited to less than $10 \%$ of the annual date production (Saudi Ministry of Agriculture, 2007). Therefore, efforts must be exerted to increase the productivity of these factories to accommodate more tonnage of raw dates produced. Accommodation of more tonnage could be achieved by either increasing the number of date factories or improving the date processing systems. Date separating and sorting are two processing steps that are conducted manually in all of the date processing plants (Al-Janobi, 2000). Manual date sorting is tedious, costly, laborious and can produce non-homogenous dates in terms of their moisture contents as the worker concentration varies along the workday, therefore, automating date sorting is very significant (Al-Janobi, 2000). Inspection and grading of food and agricultural products by human inspectors are inaccurate, labor intensive and time consuming operations (Ni et al., 1997; Heinemann et al., 1994). On the other hand, automating the date sorting process can greatly contribute into the productivity of the date factories; consequently, increasing the amount of total date production that can be accommodated by these factories.

A practical, rapid moisture sensor for individual fruits (dates) can provide the means to automatically sort dates based on their moisture contents. Thereby, the amount of skilled labor required can significantly be reduced resulting in a more cost efficient operation and more stable industry (Al-Janobi, 2000). Automatic sensing of individual date moisture content can be efficiently used to separate high-moisture dates at harvest from those that do not require drying and careful grading, thus the quantity of material to be manually graded can be greatly reduced (Nelson and Lawrence, 1992 and 1994). In addition, human error in sorting can be eliminated producing more homogenous dates.

The need for on line moisture sensing devices has initiated studies on ways to instantaneously sense moisture content of whole individual dates nondestructively (Nelson and Lawrence, 1992 and 1994). The overall goal of this study was to participate in fulfilling this need by developing a practical inexpensive electronic date moisture sensor that can be integrated into a complete automatic date processing line to nondestructively sort highmoisture from low-moisture dates.

\section{REVIEW OF LITERATURE}

Date fruit processing and industry has not seen as much development as with other fruits. In most packing houses and processing plants, dates are 
still hand sorted and graded as they move along on conveyors or oscillating tables. However, studies and researches have been conducted to participate in the effort to automate date sorting process. One of these studies depended on the technology of machine vision. This technology has been widely utilized in the field of agriculture and food industry to sort and grade numerous agricultural and food products (Ahmad and Reid, 1991; Miller and Delwiche, 1989; Okamura et al., 1991). A study by Wulfson et al. (1989) revealed that date surface color and texture were two determinant factors that could be efficiently used to sort dates using the technology of machine vision. Al-Janobi (2000) conducted a study to inspect dates by color machine vision. He used histogram feature means, variance and wrinkle ratio to grade a local date type (Sifri) into four quality categories based on a color threshold technique.

Individual dates are different in terms of texture composition, color, shape, size and sugar and moisture contents. The variation in date moisture content produces different date elasticity, which hand sorters use, by feel, as one criterion for date sorting and grading (Chesson et al., 1979). Date moisture content is a factor that influences color, uniformity of size, surface defects and texture, which are criteria usually used for date sorting (Nelson and Lawrence, 1992). Thus, moisture content can be used as a factor based on which dates can be sorted. However; the conventional oven method to determine date moisture content was thought to be destructive to the fruit and labor and time-consuming (Ismail and Alyahya, 2003). On the other hand, the electric meter method was described by Nelson and Lawrence (1994) to be more appropriate for laboratory work since it required grinding of the subject materials. Ismail and Alyahya (2003) developed a sensor to instantaneously detect date moisture content using a modified Colpitts oscillator and 2N743 transistor. The sensor produced a voltage proportional to date moisture content. A linear relationship between the sensor voltage output and date moisture content was obtained. The $\mathrm{R}^{2}$ value of this relationship was $95 \%$. Results of the study revealed that the sensor was responsive and accurate in measuring date moisture content.

\section{MATERIALS AND METHODS}

\section{Development of the Sensor}

Dates, as a food product, can transfer an electric current if it is moist. It was found that the electrical resistance of agricultural was proportional to 
the moisture content (Kandala and Nelson, 1990). Previous researches on the electrical properties of dates, such as electrical resistance, electrical conductivity, and the dielectrical properties, indicated that date moisture content could be successfully measured using a moisture sensor that could be based on any of these properties. Thus sensor in this study was developed on the basis of electrical resistance property. It was designed to measure the electrical resistance of date tissue as the current passed through it, and produce a voltage signal proportional to the electrical resistance of date tissue. The sensor output (voltage signal) was amplified utilizing an operational amplifier and displayed on a digital multimeter screen. A Wheatstone bridge was incorporated in the sensor's circuit (shown in figure 1) to generate a voltage signal $\left(V_{o}\right)$ greater than zero when the balance of the bridge arm, where $V_{o}=0$, was disturbed. Disturbance occurred as a result of a change in sensor resistance $\left(\mathrm{R}_{\mathrm{S}}\right)$ due to a change in the sensed moisture of the medium (dates) under study. The voltage signal $\left(\mathrm{V}_{\mathrm{o}}\right)$ was found to be proportional to the changes in $R_{S}\left(\Delta R_{S}\right)$. Sensor sensitivity $(K)$ can be determined as:

$$
\mathrm{K}=\frac{\mathrm{V}_{\mathrm{o}}}{\Delta \mathrm{R}_{\mathrm{s}}}=\frac{\mathrm{V}}{4 \mathrm{R}}
$$

Parameters in equation 1 were designed to obtain the maximum sensitivity of the developed sensor. The value of input voltage to the Wheatstone bridge circuit (V), appearing in equation 1 , was set to 9 volts.

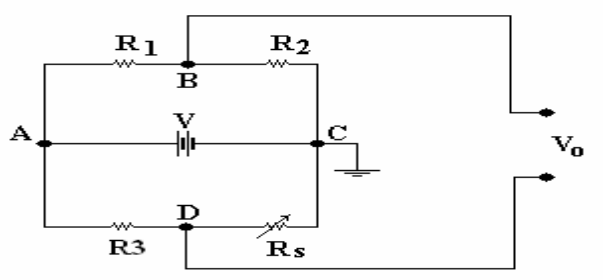

Figure1: The electrical circuit diagram as a part of the date moisture sensor.

A differential amplifier, shown in figure 2, was used to amplify the value of the output voltage of the sensor $\left(\mathrm{V}_{\mathrm{o}}\right)$. Nilsson (1983) reported that in order to predict the behavior of an operational amplifier when circuit elements are externally connected to its terminals, the constraints imposed on the terminal voltages and currents by the amplifier itself must be understood as follows: $\quad \mathrm{V}_{\mathrm{amp}}=\mathrm{A}$ Vo

And

$$
-\mathrm{V}_{\mathrm{cc}} \leq \mathrm{V}_{\mathrm{amp}} \leq+\mathrm{V}_{\mathrm{cc}}
$$


Where; $\mathrm{V}_{\mathrm{amp}}$ is the amplifier voltage output,

$\mathrm{A}$ is a constant defined as the open-loop voltage gain,

Vo is the sensor voltage output,

$\mathrm{V}_{\mathrm{cc}}$ is the power supply voltage to the amplifier.

Equation 2 states that the output voltage $\left(\mathrm{V}_{\mathrm{amp}}\right)$ is proportional to the voltage $\mathrm{V}_{\mathrm{o}}$, where the proportionality constant (A) is known as the open-loop voltage gain. However, equation 3 states that the output voltage of the amplifier $\left(\mathrm{V}_{\mathrm{amp}}\right)$ is bound by the power supply voltages. If $\mathrm{V}_{\mathrm{amp}}$ is at either limiting value of the Vcc, the operational amplifier becomes saturated. The amplifier is operating in its linear range as long as $\mathrm{V}_{\mathrm{amp}}<\left|\mathrm{V}_{\mathrm{cc}}\right|$.

The output of the amplifier that expresses both of the two previous equations ( 2 and 3 ) is shown in figure 3 . The importance of the voltage constraints lies in knowing the typical numerical values of $V_{c c}$ and $A$. The dc power supply voltage $\left(\mathrm{V}_{\mathrm{cc}}\right)$ seldom exceeds $20 \mathrm{v}$ and $\mathrm{A}$ is rarely less than $10000\left(10^{4}\right)$ (Nilsson, 1983). Therefore, the magnitude of $V_{o}$ in the linear range of operation must be less than the value of. $\frac{V_{c c}}{A}=\frac{20}{10^{4}}$ or $2 \mathrm{mv}$. Due to this fact, Nilsson (1983) concluded that when the operational amplifier was operating in its linear region, the value of $\mathrm{V}_{\text {amp }}$ became very small.

The differential amplifier was incorporated in the sensor's circuit as shown in figure 4. Figure 5 illustrates the complete experimental setup that was developed to sense the date moisture content. The voltage transformer shown in figure 5 was used to supply a voltage of $9 \mathrm{v}$ to both of the electronic circuit and the multimeter. Sensing the moisture content was performed by placing a single date between the sensor's electrodes and recording the resulted output voltage from the amplifier that was displayed by the multimeter. Variations in date moisture content caused the resistance on the transistor to vary accordingly, which allowed the use of the output voltage as a function of date moisture content.

\section{Determination of Date Moisture Contents}

Four freshly harvested types of dates (Sokkari, Rawthana, Om alkhashab and Nabtat Ali) were selected for the study as they were the most common types of dates in Al-Gaasim region in Saudi Arabia. A sample of about $1 \mathrm{~kg}$ of each type was acquired and the four samples were mixed to form one major sample of about $4 \mathrm{~kg}$. Dates in the major sample were initially classified into three groups based on their moisture; dry, medium and moist. This initial classification was performed by hand sensing the 
softness of the dates, on the basis that the softer the date the more moisture it contained.

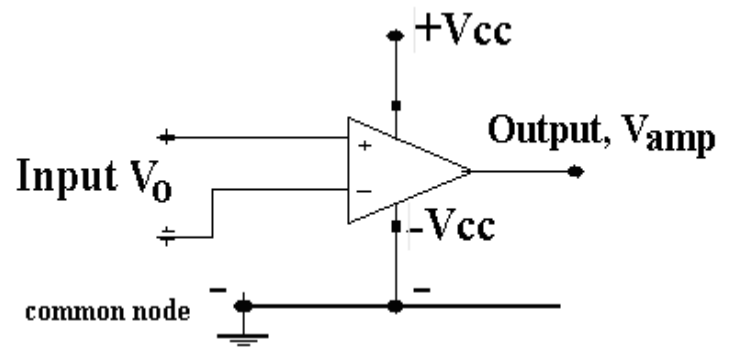

Figure 2: Terminal voltage variables of the ideal differential amplifier.

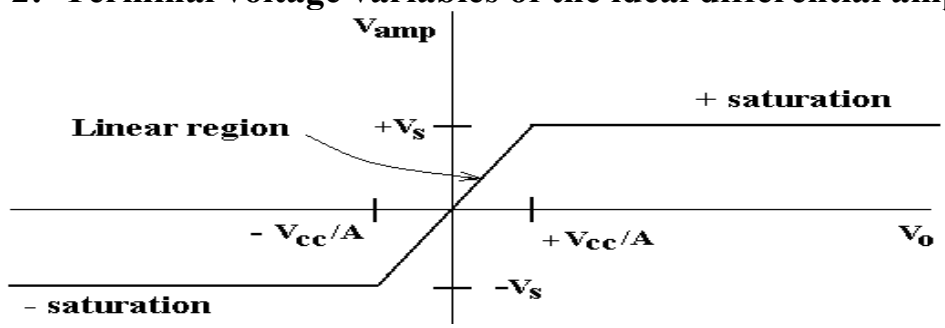

Figure 3: Voltage transfer characteristics of the amplifier, Vs is the saturation voltage.

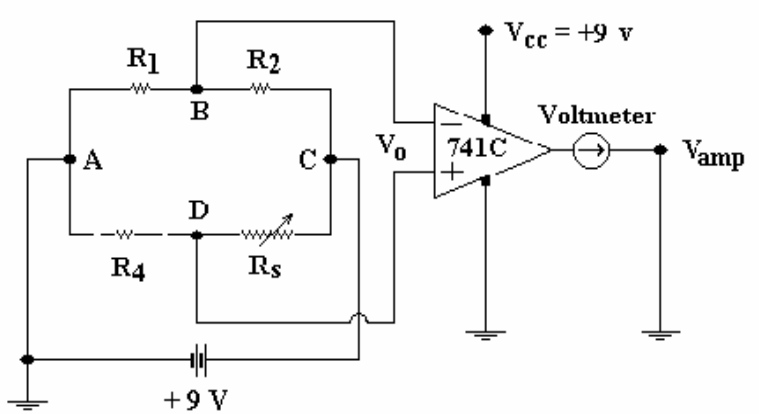

Figure 4: The amplifier incorporated in the sensor's circuit.

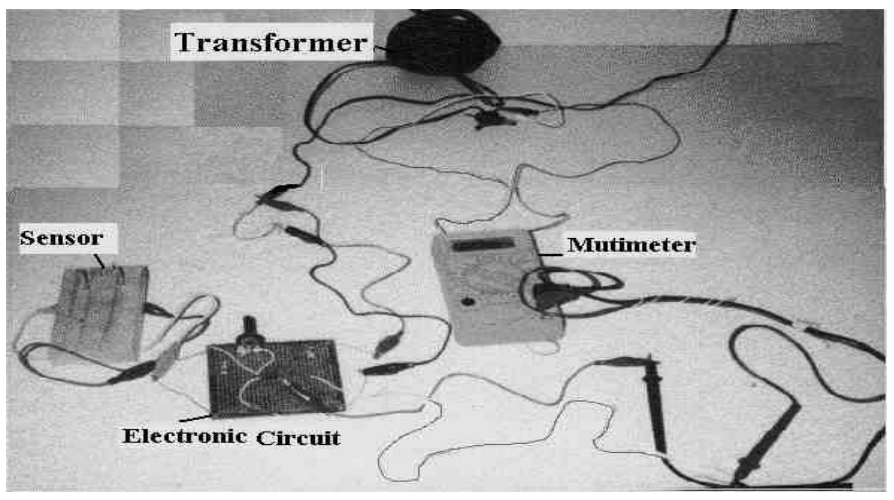

Figure 5: Complete Experimental setup. 
An electrical scale (LIBROR EB-4000H) with a capacity of 4000.00 $\mathrm{g}$ and an accuracy of $0.01 \mathrm{~g}$ was used to obtain $5 \mathrm{~g}$ samples from each of the three groups of dates. On the wet basis, date moisture contents were determined following the standard procedure outlined by Rygg (1948) and Barreveld (1959).

\section{RESULTS AND DISCUSSION}

In a previous study by Ismail and Alyahya (2003), a strong correlation between date moisture content and a sensor output voltage was revealed. However, the output voltage was very low even at high date moisture contents. The output voltage did not exceed $1.4 \mathrm{v}$ even at a high moisture content of more than $40 \%$. As a result, the use of this sensor to actuate a mechanical device was basically limited or even not possible. The new sensor electronic circuit introduced in this study was instrumented with a differential amplifier, or sometimes referred to as an operational amplifier, which has become increasingly important in recent years as it is a basic building block in the design of analog computers (Nilsson, 1983). The purpose of using the amplifier was to generate a voltage output enough to activate a mechanical device that can be part of an automatic date sorting systems.

The date moisture content values were plotted against the sensor output voltage as shown in figure 6 . The effect of the amplifier on the voltage output was evident as a voltage of more than $5 \mathrm{v}$ was produced with a moisture content that was as low as $2.5 \%$. A voltage of $6 \mathrm{v}$ or above was produced as a response to moisture contents that were in the vicinity of $40 \%$ or more.

Results shown in figure 6 depict the actual behavior (effect) of the amplifier on the sensor voltage output. The actual behavior of the amplifier reflects its expected theoretical behavior illustrated in figure 3. The linear region shown in figure 3 was actually reproduced in figure 6 , where a narrow linear region between $5.5 \mathrm{v}$ to $6.2 \mathrm{v}$, corresponding to moisture content values between $26 \%$ and $38 \%$, was formed by actual data points. In the linear region, the sensor was found to be very sensitive to changes in moisture content values, where an increase in the moisture content value from $27 \%$ to $38 \%$ resulted in an increase in the voltage output from $5.6 \mathrm{v}$ to $6.2 \mathrm{v}$. The majority of the date moisture data points formed two groups, one at each end of the linear region (figure 6). One group of the data points 
included the samples with moisture content values that ranged between $2.5 \%$ and $26 \%$, which generated an output voltage of less than $5.5 \mathrm{v}$. The sensor was observed to maintain a very low sensitivity to changes in moisture contents within this group. The other group, however, included the samples that were associated with moisture content values of $38 \%$ and above, which generated an output voltage of more than $6 \mathrm{v}$. A reasonable sensor sensitivity was exhibited to changes in moisture content values among data points in this group. Based on the sensor output voltage, the majority of the samples in this study were basically separated into two groups, one with high moisture content (generating high voltage output) and the other with low moisture content (generating low voltage output). This criterion can be exploited to control the operation of a DC-motor that would actuate a gate in a mechanical sorting system. The DC-motor can be set to operate at a voltage of $5.5 \mathrm{v}$ or above, thereby, it would open the gate to route the high moisture content dates (above 26\%), that would generate the required voltage, to another path in the processing line.

\section{CONCLUSTIONS}

A non-destructive method employing an electronic sensor was developed to detect date moisture content. The sensor was instrumented with a signal amplifier to amplify the senor output voltage to a value that could be utilized to operate a mechanical date-moisture based automatic sorting system. Specific conclusions from the study include the following:

- The date moisture content can be non-destructively sensed using the developed electronic circuit that contains a Wheatstone bridge sensor and an operational amplifier.

- The amplifier was able to elevate the sensor output voltage to more than $5.5 \mathrm{v}$ when the date moisture content reached more than $26 \%$. This voltage can be utilized to operate a DC-motor, which in turn, can open a gate in a mechanical automatic sorting system.

- Based on the output voltage of the developed sensor, a non-destructive automatic moisture-based sorting system can be developed to classify dates into two groups. One includes the dates that do not require drying (moisture content of less than 26\%), and the other includes the dates that require drying (moisture content of more than $26 \%$ ). 


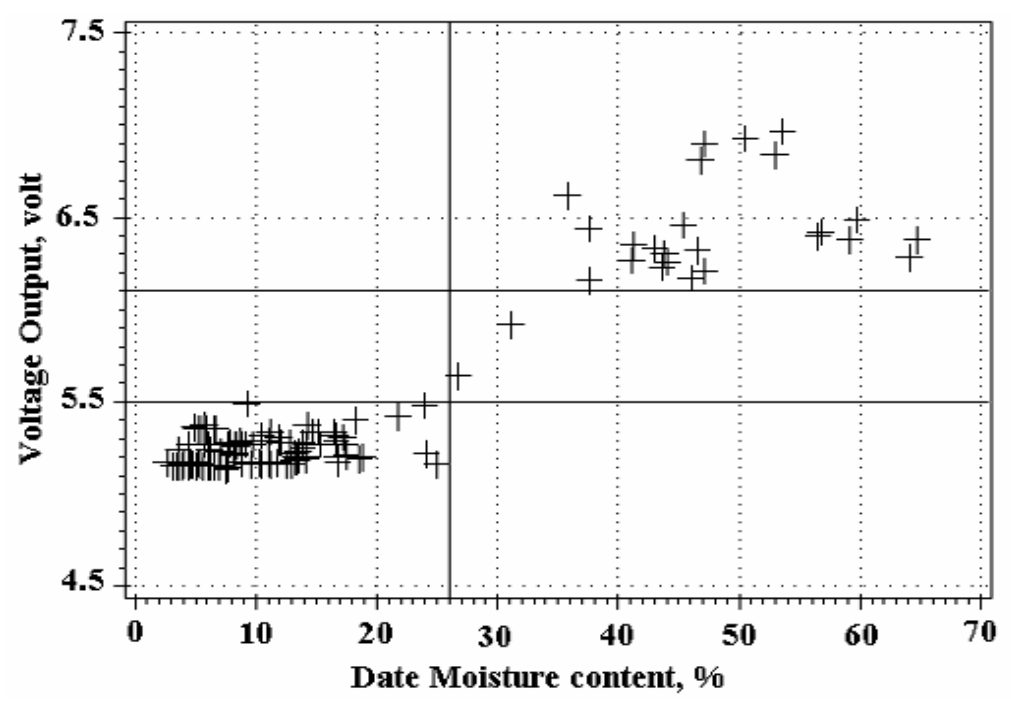

Figure 6: Sensor output voltage versus date moisture contents.

\section{REFERENCES}

Ahmad, S.I. and J.F. Reid. 1991. Computer vision technique for detecting color changes in stressed corn. ASAE Paper No. 91-3052. MI: ASAE.

Al-Janobi, A.A. 2000. Date inspection by color machine vision. Journal of King Saud University. K. S. U., Riyadh, Saudi Arabia, Vol. 12: 61-70.

Barreveld, W.H. 1959. Processing the coastal date. Rome, Italy: United Nations, Food and Agriculture Organization.

Chesson, J.H., P.F. Burkner and R.M. Perkins. 1979. An experimental vacuum separator for dates. Trans. ASAE. 22(1): 16-20.

Heinemann, P.H., R. Hughes, C.T. Morrow, H.J. Sommer, R.B. Beelman, and P.J. Wuest. 1994. Grading mushrooms using a machine vision system. Trans. ASAE 37(5): 1671-1677.

Ismail, K.M. and S.A. Alyahya. 2003. A quick method for measuring date moisture content. Trans. ASAE 46(2): 401-405.

Kandala, C.V.K. and S.O. Nelson. 1990. Measurement of moisture content in single kernels in peanuts: a nondestructive electrical method. Trans. ASAE 32(2): 567-571.

Miller, B.K. and M.J. Delwiche. 1989. A color vision system for peach grading. Trans. ASAE 32(4): 1484-1490.

Nelson, S.O. and K.C. Lawrence. 1992. Sensing moisture content in dates by RF impedance measurements. Trans. ASAE 35(2): 591-596.

Nelson, S.O. and K.C. Lawrence. 1994. RF impedance sensing of moisture content in individual dates. Trans. ASAE 37(3): 887-891. 
Ni, B., M.R. Paulsen, K. Liao and J.F. Reid. 1997. Design of an automated corn kernel inspection system for machine vision. Trans. ASAE 40(2): 491-497.

Nilsson, J.W. 1983. Electronic circuits. The operational amplifier. Pp:240275. Addison-Wesley pub. Co. USA.

Okamura, K. Nancy, M.J. Delwiche and J.F. Thompson. 1991. Ra isin grading by machine vision. ASAE Paper No. 91-7011. ASAE.

Rygg, G.L. 1948. Storage humidity for dates. Date Grower's inst. Rept. 25: 34-35.

Saudi Ministry of Agriculture. 2007. Statistical indicators on date industry in the SAK. Agricultural research and development affairs, department of studies, planning and statistics, $11^{\text {th }}$ issue. Riyadh, Saudi Arabia.

Saudi Ministry of Agriculture. 2008. Agricultural statistical year book. Agricultural research and development affairs, department of studies, planning and statistics, $21^{\text {st }}$ issue. Riyadh, Saudi Arabia.

Wulfson, D., Y. Sarig and R.V. Algazi. 1989. Preliminary investigation to identify parameters for sorting of dates by image processing. ASAE Paper No. 89-6610. St. Joseph, MI: ASAE.

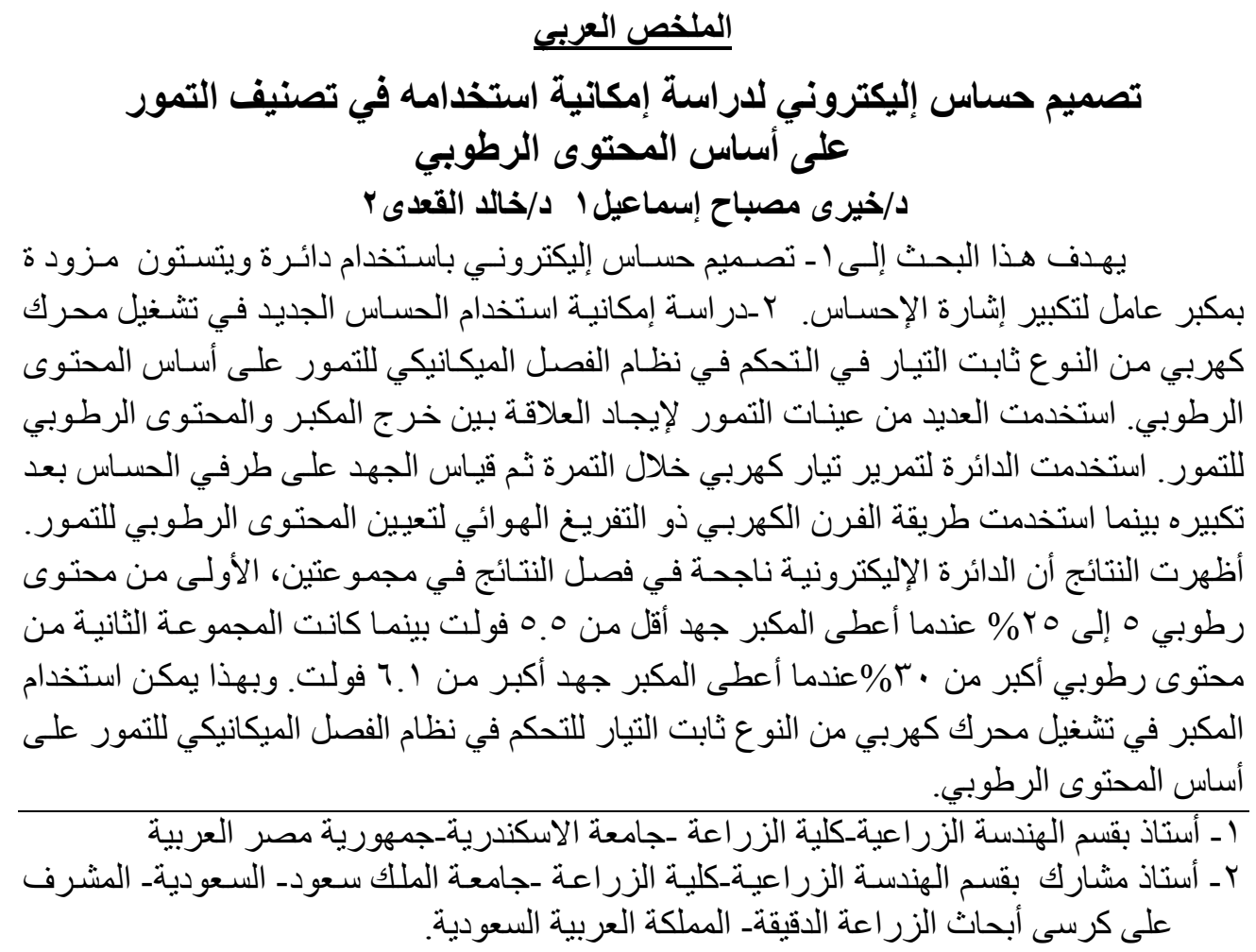

Misr J. Ag. Eng., October 2009 